\title{
Profil pasien tuberkulosis dengan multi drug resistance (MDR) di RSUP Prof. Dr. R. D. Kandou periode Agustus 2015 - Agustus 2016
}

\author{
${ }^{1}$ Andreas G. H. Siahaan \\ ${ }^{2}$ Efata B. I. Polii \\ ${ }^{2}$ Jeffrey Ongkowijaya
}

\author{
${ }^{1}$ Kandidat Skripsi Fakultas Kedokteran Universitas Sam Ratulangi Manado \\ ${ }^{2}$ Bagian Ilmu Penyakit Dalam Fakultas Kedokteran Universitas Sam Ratulangi Manado \\ Email:23aghs@gmail.com
}

\begin{abstract}
Multidrug Resistance Tuberculosis (MDR-TB) is a serious health problem in society towards the effort to eliminate TB and its prevention in global scale as well as in Indonesia. MDR-TB incidence is difficult to determine because sputum propagation and medicine sensitivity test is not routinely implemented in places with high prevalence. The raising of TB MDR is influenced by several factors, as follows: the patients, caregivers, and medical service factors. This study was aimed to determine the profile of TB-MDR patients treated at Prof. Dr. R. D. Kandou Hospital Manado from August 2015 to August 2016. This was a descriptiveretrospective study based on secondary data of the medical record in period August 2015 August 2016 at Prof. Dr. R. D. Kandou Hospital Manado. The results showed that of 30 patients who met the inclusion criteria, the highest percentages were in males (67\%), age range 41-50 years $(36 \%)$, senior high school as the latest education (54\%), patients originated from Manado (63.33\%), normal nutrition status (57\%), and the GeneXpert result was medium (56\%). The most common comorbidity was type 2 DM (23\%). Conclusion: In this study, the majority of MDRTB patients were males, age range 41-50 years, senior high school as the last education was SLTA, originated from Manado, normal nutrition status, and the GeneXpert resulted in medium. Morbidities of most patients experienced is DM type 2.
\end{abstract}

Keywords: TB, TB MDR, genexpert

\begin{abstract}
Abstrak: Multidrug resistance tuberculosis (TB MDR) memrupakan masalah kesehatan yang serius di dalam masyarakat terhadap pemberantasan TB serta pencegahannya baik dalam skala dunia maupun di Indonesia. Kejadian TB MDR sulit ditentukan karena biakan sputum dan uji kepekaan obat tidak rutin dilaksanakan di tempat-tempat dengan prevalensi tinggi. Peningkatan TB MDR dipengaruhi oleh beberapa faktor seperti faktor pasien, pemberi pelayanan, dan sistem pelayanan kesehatan. Penelitian ini bertujuan untuk mengetahui profil pasien TB MDR yang berobat di RSUP Prof. Dr. R.D. Kandou Manado periode Agustus 2015 - Agustus 2016. Jenis penelitian ialah deskriptif-retrospektif berdasarkan data sekunder dari catatan rekam medik pada periode Agustus 2015-Agustus 2016 di RSUP Prof. Dr. R. D. Kandou Manado. Hasil penelitian memperlihatkan dari 30 data rekam medik pasien yang memenuhi kriteria inklusi, ditemukan lebih banyak pasien berjenis kelamin laki-laki (67\%), rentang usia 41-50 tahun (36\%), berpendidikan terakhir SLTA (54\%), asal daerah Manado (63,33\%), gizi normal (57\%), dan hasil GeneXpert medium (56\%). Penyakit penyerta terbanyak ialah DM tipe 2 (23\%) Simpulan: Pada studi ini didapatkan pasien TB MDR terbanyak berjenis kelamin laki-laki, dengan rentang usia pasien 41-50, pendidikan terakhir SLTA, dan asal daerah Manado. Pasien terbanyak memiliki gizi normal dan hasil GeneXpert medium dengan penyakit penyerta DM tipe 2.
\end{abstract}

Kata kunci: TB, TB MDR, genexpert

Tuberkulosis (TB) merupakan penyakit infeksi yang sejarahnya dapat dilacak sampai ribuan tahun sebelum masehi. ${ }^{1,2}$

Tuberculosis Multidrug Resistance (TB 
MDR) atau yang lebih dikenal dengan tuberkulosis resistensi obat ganda adalah masalah kesehatan yang serius didalam masyarakat terhadap pemberantasan TB serta pencegahannya, baik dalam skala dunia maupun Indonesia. Tuberculosis Multidrug Resistance (TB MDR) merupakan isolat Mycobacterium tuberculosis yang resisten terhadap minimal dua jenis obat anti TB (OAT) lini pertama yaitu rifampisin dan isoniazid.,

Berdasarkan data WHO tahun 2014, dilaporkan terdapat enam juta kasus baru TB di dunia. Indonesia termasuk salah satu negara dengan jumlah kasus TB MDR tertinggi di dunia. Total kasus TB MDR di Indonesia yang telah dilaporkan yaitu 1.812 kasus pada tahun $2014 .^{5}$

Kejadian TB MDR sulit ditentukan karena biakan sputum dan uji kepekaan obat tidak rutin dilaksanakan di tempattempat dengan prevalensi $\mathrm{TB}$ tinggi. TB MDR merupakan masalah besar yang terus meningkat dan diperkirakan TB MDR akan tetap menjadi masalah di banyak wilayah dunia. ${ }^{4,6}$ Menurut WHO, bila pengendalian TB tidak benar, prevalensi TB MDR mencapai 5,5\%, sedangkan dengan pengendalian yang benar yaitu dengan menerapkan strategi Directly Observed Treatment Shortcourse (DOTS), maka prevalensi TB MDR hanya 1,6\% saja. ${ }^{3}$

Peningkatan kasus TB MDR baik secara morbiditas maupun mortalitas diduga disebabkan oleh 3 faktor yaitu: (1) faktor pasien, seperti berobat tidak teratur, kurangnya informasi, masalah keuangan, transportasi, dan lain-lain; (2) faktor pemberi pelayanan kesehatan, seperti paduan pengobatan yang tidak adekuat, menambahkan satu obat pada paduan yang gagal, pengobatan tidak berdasarkan uji kepekaan, tidak ada atau kurangnya pantauan; dan (3) faktor sistem pelayanan kesehatan, seperti ketidaktersediaan obat, kualitas obat dan kondisi penyimpanan obat yang buruk, organisasi yang lemah, tidak mendapat dukungan dana yang cukup, tidak ada sosialisasi pedoman pengobatan serta terbatasnya fasilitas laboratorium. ${ }^{4,7}$

Berdasarkan latar belakang diatas, maka peneliti tertarik ingin melakukan penelitian tentang profil pasien TB MDR di RSUP Prof. Dr. R. D. Kandou Manado.

\section{METODE PENELITIAN}

Jenis penelitian ini adalah deskriptif retrospektif, yaitu mengetahui profil pasien TB MDR yang berobat di RSUP Prof. dr. R. D. Kandou pada bulan Agustus 2015 Agustus 2016. Pasien yang diambil menjadi sampel ialah yang memenuhi kriteria inklusi, yaitu seluruh pasien yang didiagnosis TB MDR yang mendapat pengobatan di RSUP Prof. Dr. R. D. Kandou periode Agustus 2015-Agustus 2016. Pasien yang masuk kriteria eksklusi ialah pasien dengan rekam medik yang tidak lengkap, rusak, maupun tidak terbaca. Variabel penelitian ini ialah jenis kelamin, usia, pendidikan, pekerjaan, IMT, asal daerah, riwayat pengobatan, hasil pemeriksaan GeneXpert MTB, dan penyakit penyerta. Pengolahan data secara manual dan hasil penelitian disajikan dalam bentuk tulisan, tabel, dan gambar.

\section{HASIL PENELITIAN}

Penelitian ini dilakukan di RSUP Prof. Dr. R. D Kandou Manado selama bulan September 2016 hingga November 2016 dan didapatkan 30 pasien TB MDR yang memenuhi kriteria inklusi dan eksklusi.

Pasien TB MDR terbanyak yaitu berjenis kelamin laki-laki sebanyak 20 orang $(67 \%)$, sedangkan pasien dengan jenis kelamin perempuan sebanyak 10 orang $(33 \%)$.

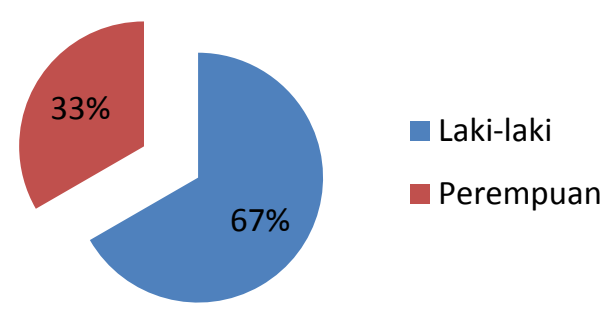

Gambar 1. Distribusi TB MDR berdasarkan jenis kelamin di RSUP Prof. Dr. R. D Kandou Manado periode Agustus 2015-Agustus 2016 
Pasien TB MDR terbanyak yang menderita TB MDR yaitu pada rentang usia 41-50 tahun sebanyak 11 orang (36\%), usia kurang dari 30 tahun sebanyak 9 orang (30\%), rentang usia 51-60 tahun sebanyak 5 orang $(17 \%)$, rentang usia 31-40 tahun sebanyak 3 orang (10\%), rentang usia 6170 tahun sebanyak 2 orang $(7 \%)$ dan tidak ditemukan pasien dengan usia diatas 70 tahun $(0 \%)$.

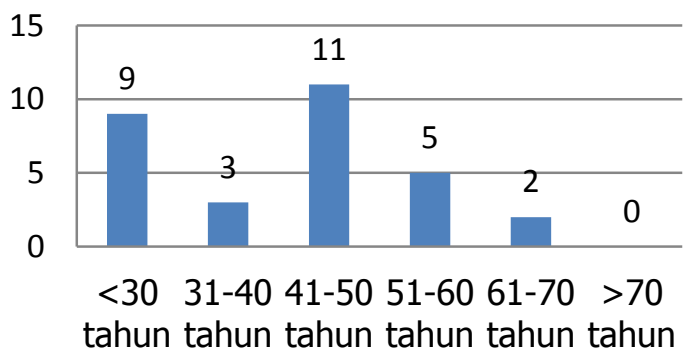

Gambar 2. Distribusi Pasien TB MDR berdasarkan usia di RSUP Prof. Dr. R. D. Kandou Manado periode Agustus 2015Agustus 2016

Berdasarkan pendidikan terakhir pasien terbanyak yaitu SLTA sebanyak 16 orang (54\%), SLTP sebanyak 6 orang (20\%), SD sebanyak 4 orang (13\%), Sarjana sebanyak 3 orang $(10 \%)$ dan yang tidak sekolah sebanyak 1 orang (3\%).

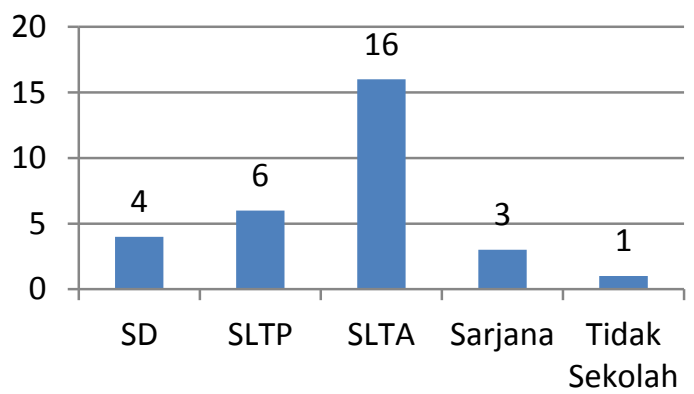

Gambar 3. Distribusi Pasien TB MDR berdasarkan pendidikan di RSUP Prof. Dr. R. D. Kandou Manado periode Agustus 2015Agustus 2016

Berdasarkan pekerjaan pasien TB MDR didapatkan 9 orang (30\%) bekerja sebagai pegawai; ibu rumah tangga sebanyak 7 orang (23\%); supir sebanyak 5 orang $(17 \%)$; pelajar, tidak bekerja, petani masing-masing sebanyak 2 orang (7\%); pendeta dokter gigi, wiraswasta masingmasing sebanyak 1 orang (3\%).

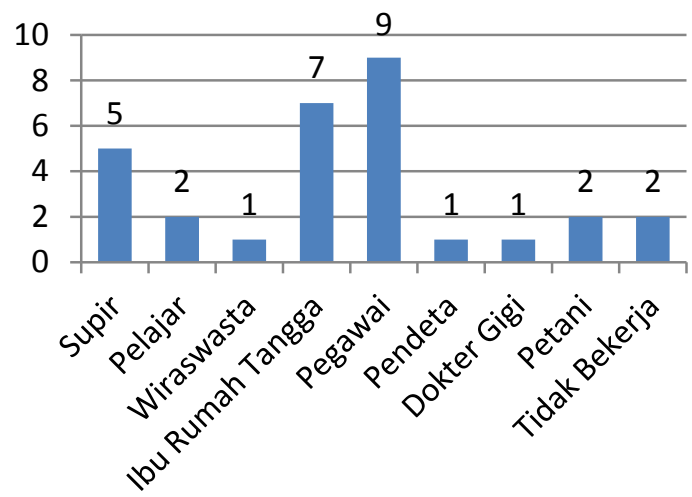

Gambar 4. Distribusi Pasien TB MDR berdasarkan pekerjaan di RSUP Prof. Dr. R. D. Kandou Manado periode Agustus 2015Agustus 2016

Tabel 1. Distribusi pasien TB MDR berdasarkan asal daerah di RSUP Prof. Dr. R. D. Kandou Manado periode Agustus 2015Agustus 2016

\begin{tabular}{lcc}
\hline $\begin{array}{l}\text { Asal Daerah Pasien } \\
\text { TB MDR }\end{array}$ & Jumlah & $\%$ \\
\hline Manado & 19 & $63,33 \%$ \\
$\quad$ Wenang & 1 & $3,33 \%$ \\
$\quad$ Singkil & 5 & $16,67 \%$ \\
$\quad$ Tuminting & 3 & $10 \%$ \\
$\quad$ Mikala & 5 & $16,67 \%$ \\
$\quad$ Wanea & 1 & $3,3 \%$ \\
$\quad$ Sario & 2 & $6,67 \%$ \\
$\quad$ Bunaken & 1 & $3,33 \%$ \\
Bitung & 1 & $3,33 \%$ \\
Siau & 1 & $3,33 \%$ \\
Minahasa & 1 & $3,33 \%$ \\
Minahasa Selatan & 1 & $3,33 \%$ \\
Minahasa Utara & 2 & $6,67 \%$ \\
Minahasa Tenggara & 1 & $3,33 \%$ \\
Bolaang Mongondow & 1 & $3,33 \%$ \\
Selatan & 1 & $3,33 \%$ \\
Bolaang Mongondow & & \\
Utara & 1 & $3,33 \%$ \\
Kotamobagu & 1 & $3,33 \%$ \\
Tomohon & 1 & \\
\hline
\end{tabular}

Pasien terbanyak berasal dari daerah Manado dengan jumlah 19 orang (63,33\%). Dari Bitung, Siau, Minahasa, Minahasa Utara, Minahasa Tenggara, Bolaang Mongondow Selatan, Bolaang Mongondow Utara, Kotamobagu, Tomohon masingmasing sebanyak 1 orang $(3,33 \%)$; Minahasa Selatan sebanyak 2 orang 
(6,67\%). Dari daerah Manado sendiri terbanyak berasal dari kecamatan Singkil dan kecamatan Tikala dimana masingmasing berjumlah 5 orang $(16,67 \%)$ (Tabel $1)$.

Pada pasien TB MDR didapatkan pasien dengan status gizi normal merupakan yang terbanyak dengan jumlah 17 orang (57\%), underweight/kekurangan gizi sebanyak 13 orang $(43 \%)$ dan tidak ditemukan pasien yang memiliki status gizi overweight/kelebihan gizi $(0 \%)$.

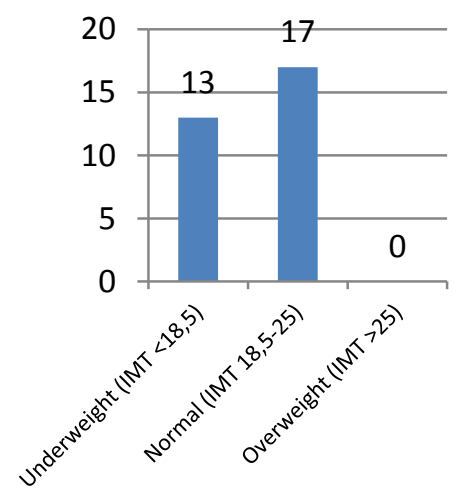

$$
\begin{aligned}
& \text { Distribusi } \\
& \text { Pasien } \\
& \text { Berdasarkan } \\
& \text { Status Gizi }
\end{aligned}
$$

Gambar 5. Distribusi Pasien TB MDR berdasarkan status gizi di RSUP Prof. Dr. R. D. Kandou Manado periode Agustus 2015Agustus 2016

Berdasarkan pemeriksaan GeneXpert ditemukan pasien TB MDR dengan hasil pemeriksaan high sebanyak 8 orang $(27 \%)$, medium sebanyak 17 orang (56\%), low sebanyak 3 orang (10\%) dan very low sebanyak 2 orang $(7 \%)$.

Tabel 2. Distribusi pasien TB MDR berdasarkan hasil pemeriksaan GeneXpert di RSUP Prof. Dr. R. D. Kandou Manado periode Agustus 2015-Agustus 2016

\begin{tabular}{ccc}
\hline $\begin{array}{c}\text { Hasil } \\
\text { Pemeriksaan } \\
\text { GeneXpert }\end{array}$ & $\begin{array}{c}\text { Jumlah } \\
\text { Pasien }\end{array}$ & \% \\
\hline High & 8 & 27 \\
Medium & 17 & 56 \\
Low & 3 & 10 \\
Very Low & 2 & 7 \\
\hline
\end{tabular}

Pasien TB MDR didapatkan penyakit penyerta pasien terbanyak ialah diabetes melitus tipe 2 sebanyak 12 pasien (35\%), diikuti dengan sindroma dispepsia sebanyak 5 orang (14\%). Hepatitis B, pneumonia dan efusi pleura, dan hipertensi masing-masing sebanyak 3 orang (9\%). Alergi obat dan AKI sebanyak 2 orang $(6 \%)$ serta gastritis sebanyak 1 orang $(3 \%)$.

Tabel 3. Distribusi pasien TB MDR berdasarkan penyakit penyerta di RSUP Prof. Dr. R. D. Kandou Manado periode Agustus 2015-Agustus 2016

\begin{tabular}{ccc}
\hline $\begin{array}{c}\text { Penyakit Penyerta } \\
\text { Pasien TB MDR }\end{array}$ & $\begin{array}{c}\text { Jumlah } \\
\text { Pasien }\end{array}$ & \% \\
\hline Alergi Obat & 2 & 6 \\
Hepatitis B & 3 & 9 \\
Sindroma Dispepsia & 5 & 14 \\
Pneumonia & 3 & 9 \\
Efusi Pleura & 3 & 9 \\
Diabetes Melitus tipe 2 & 12 & 35 \\
AKI & 2 & 6 \\
Hipertensi & 3 & 9 \\
Gastritis & 1 & 3 \\
\hline AKI : Acute Kidney Injury & &
\end{tabular}

Berdasarkan riwayat pengobatan TB MDR didapatkan jumlah pasien yang sudah lebih dari 1 kali berobat yaitu sebanyak 15 orang pasien $(50 \%)$, begitu juga dengan pasien yang baru pertama kali berobat yaitu sebanyak 15 orang pasien $(50 \%)$

Tabel 4. Distribusi pasien TB MDR berdasarkan riwayat pengobatan di RSUP Prof. Dr. R. D. Kandou Manado periode Agustus 2015-Agustus 2016

\begin{tabular}{ccc}
\hline $\begin{array}{c}\text { Riwayat } \\
\text { pengobatan }\end{array}$ & Jumlah & \% \\
\hline 1 kali & 15 & 50 \\
$>1$ kali & 15 & 50 \\
\hline
\end{tabular}

\section{BAHASAN}

Pada penelitian yang dilakukan didapatkan pasien TB MDR berdasarkan jenis kelamin terbanyak adalah pria dengan jumlah 20 orang pasien $(67 \%)$ dan wanita berjumlah 10 orang pasien (33\%). Rentang usia terbanyak adalah antara 41-50 tahun sebanyak 11 orang $(36 \%)$. Hal yang sama juga ditemukan dalam penelitian sebelumnya oleh Munir dan Munawwarah dimana pria cenderung lebih banyak menderita TB MDR dan lebih banyak 
ditemukan pada usia produktif. Hal ini mungkin dikarenakan pekerjaan, gaya hidup dan interaksi yang dilakukan di lingkungan sekitar oleh pria lebih berpotensi untuk terpajan kuman $\mathrm{M}$. tuberkulosis. Tidak ada hubungan yang jelas yang sebenarnya dapat menjelaskan kejadian TB MDR dengan jenis kelamin. Pria menjadi faktor lebih berisiko untuk terkena TB MDR dengan alasan wanita lebih disiplin dalam meminum obat, sedangkan ada juga yang mengatakan bahwa wanita lebih rentan terkena $\mathrm{TB}$ MDR dikarenakan sering datang terlambat untuk berobat sehingga sering datang dengan penyakit yang lebih berat dan memiliki perasaan malu serta takut dikucilkan oleh keluarga dan lingkungan sekitarnya. ${ }^{8-10}$

Berdasarkan status pendidikan dan pekerjaan pasien didapatkan pasien dengan pendidikan terakhir terbanyak adalah SLTA dengan jumlah 16 orang pasien (54\%) dan pekerjaan terbanyak adalah pegawai dengan jumlah 9 orang pasien (30\%), hal ini juga sesuai dengan penelitian yang dilakukan Munawwarah dimana didapatkan pasien dengan jenjang pendidikan terbanyak yaitu SLTA sebesar $46,7 \%$ dan oleh Nofizar sebesar $48 \%$. Lingkungan pekerjaan dan ruang lingkup interaksi yang sering dengan orang lain dapat mempengaruhi tingkat penularan akibat adanya kontak dengan orang yang menderita TB. Beberapa studi mengatakan bahwa tingkat pendidikan tidak selamanya bermakna akan kejadian TB MDR dikarenakan tidak selamanya penderita yang memiliki pendidikan dasar tingkat pengetahuannya tentang TB rendah, dan juga tidak semua yang memiliki tingkat pendidikan menengah ke atas memiliki pengetahuan tentang TB yang tinggi, hal ini diakibatkan karena pada saat ini sudah banyak media yang memberikan informasi tentang pentingnya pengobatan TB seperti iklan-iklan yang tayang pada televisi dan radio, leaflet-leaflet yang berada di puskesmas dan spanduk serta poster yang tersebar dimana-mana. ${ }^{9-12}$

Berdasarkan hasil status gizi pada penelitian ini ditemukan 13 orang pasien yang memiliki IMT <18,5 (underweight), 17 orang pasien yang memiliki IMT 18,525 (normal) dan tidak ditemukan pasien dengan IMT > 25 (overweigth), hal ini tidak sesuai dengan penelitian yang sebelumnya yang dilakukan Tartianna dan Setyarini dalam Mulyanto dimana berdasarkan penelitian yang dilakukan ditemukan pasien yang memiliki gizi kurang sebanyak $73 \%$ oleh Tartiana dan $61,5 \%$ pasien gizi kurang oleh Setyarini. Perbedaan hasil dapat disebabkan oleh adanya perbedaan sampel yang digunakan dalam penelitian ini dan penelitian sebelumnya. Dalam penelitian yang dilakukan banyak pasien yang mengeluhkan penurunan nafsu makan dan penurunan berat badan tetapi pasien masih memiliki nilai IMT yang normal. Banyak diketahui bahwa status gizi yang rendah ditemukan lebih sering terjadi pada penderita tuberkulosis aktif yang berujung pada keadaan resisten daripada penderita yang menjadi sehat. Hal ini disebabkan karena penderita TB sering mengalami penurunan nafsu makan. ${ }^{12}$

Hasil pemeriksaan GeneXpert terbanyak didapat yaitu TB MDR Medium dengan jumlah 17 orang pasien $(56 \%)$. TB MDR High ditemukan pada 8 orang pasien (27\%), Low ditemukan pada 3 orang pasien (10\%), dan Very Low ditemukan pada 2 orang pasien (7\%). Pemeriksaan GeneXpert dengan hasil resisten rifampisin dihubungkan dengan mutasi pada gen rpoB yang dikode $\beta$-subunit RNA polymerase pada $\mathrm{M}$. tuberkulosis. $^{13}$ Indikasi dilaksanakannya pemeriksaan GeneXpert ialah pasien dengan kasus TB paru kronik, pasien TB paru gagal pengobatan kategori I, pasien yang pernah diobati TB termasuk OAT lini kedua, pasien TB paru gagal pengobatan kategori II, TB paru kasus sembuh, TB dengan HIV, pasien TB yang lalai pada pengobatan kategori I maupun kategori II.

Penyakit penyerta yang paling sering ditemukan dalam penelitian ini ialah DM tipe 2 yaitu sebanyak 12 orang pasien (35\%) dan diikuti dengan sindroma dispepsia dialami oleh 5 orang pasien (9\%). Hepatitis B, pneumonia, efusi pleura dan 
hipertensi masing masing dialami oleh 3 orang pasien $(9 \%)$. Alergi obat dan AKI juga alami 2 orang pasien $(6 \%)$ dan gastritis dialami oleh 1 orang pasien (3\%). Hal ini juga sesuai dengan penelitian yang dilakukan Susanty di RSUP H. Adam Malik Medan dimana ditemukan pasien dengan penyakit penyerta DM sebanyak 10 orang pasien $(23,81 \%)$. DM tipe 2 merupakan faktor resiko TB dan berhubungan dengan TB MDR yang mempengaruhi hasil akhir pengobatan TB dan keadaan penyakit yang menyebabkan gagalnya pengobatan dan menurunnya imunitas terhadap TB oleh karena DM meningkatkan kesensitifan terhadap infeksi dengan strain yang resisten obat. ${ }^{13}$

Pada penelitian ini juga ditemukan bahwa daerah asal pasien yang terbanyak yaitu berasal dari Manado dengan jumlah 19 orang pasien $(63,33 \%)$, diikuti dari daerah Minahasa Selatan sebanyak 2 orang pasien $(6,67 \%)$. Dari daerah Bitung, Siau, Minahasa, Minahasa Utara, Minahasa Tenggara, Bolaang Mongondow Selatan, Bolaang Mongondow Utara, Kotamobagu dan Tomohon masing-masing sebanyak 1 orang pasien $(3,33 \%)$. Dari daerah Manado sendiri daerah asal pasien terbanyak berasal dari kecamatan Singkil dan Tikala yang masing-masing berjumlah 5 orang pasien $(16,67 \%)$.

Berdasarkan hasil penelitian ini, riwayat pengobatan pasien TB MDR didapatkan jumlah pasien yang sudah lebih dari 1 kali berobat yaitu sebanyak 15 orang pasien (50\%), begitu juga dengan pasien yang baru pertama kali berobat yaitu sebanyak 15 orang pasien $(50 \%)$. Hasil ini bertentangan dengan penelitian yang dilakukan Nofizar di RS Persahabatan Jakarta bahwa didapat $92 \%$ pasien mendapat pengobatan lebih dari 1 kali dan menyimpulkan bahwa pengobatan lebih dari 1 kali menjadi faktor resiko yang lebih tinggi untuk terjadinya resistensi OAT, hal ini dapat disebabkan oleh adanya perbedaan sampel yang digunakan dalam penelitian ini dan penelitian sebelumnya. ${ }^{10}$

\section{SIMPULAN}

Dari hasil penelitian terhadap pasien dengan penyakit TB-MDR terbanyak ditemukan pada laki-laki, rentang usia 4150 tahun, pendidikan terakhir SLTA, pekerjaan pegawai, asal dari Manado, status gizi pasien normal, dan hasil GeneXpert medium. Penyakit penyerta yang dialami pasien terbanyak yaitu diabetes melitus tipe 2. Berdasarkan riwayat pengobatan diperoleh hasil yang sama untuk pasien yang lebih dari 1 kali pengobatan dan yang baru 1 kali pengobatan.

\section{SARAN}

Disarankan untuk penyuluhan tentang pentingnya informasi dan edukasi TB serta TB MDR kepada masyarakat dan agar pasien lebih mengontrol penyakit penyerta karena dapat berdampak buruk terhadap hasil akhir pengobatan.

\section{DAFTAR PUSTAKA}

1. Djojobroto RD. Respirologi (Respiratory medicine) (2nd ed). Jakarta: EGC, 2015.

2. Amin Z, Bahar A. Tuberkulosis Paru. In: Sudoyo AW, Setiyo HB, Alwi I, Simadibrata M, Setiati S, editors. Buku Ajar Ilmu Penyakit Dalam (5th ed). Jakarta Pusat: Interna Publishing, 2009; p. 2230-9.

3. Rahajoe NN, Basir D, Makmuri, Kartasasmita CB. Pedoman Nasional Tuberkulosis Anak (2nd ed). Jakarta: UKK Respirologi PP IDAI, 2008; p. 1-117.

4. Perhimpunan Dokter Paru Indonesia. Pedoman Diagnosis dan Penatalaksanaan di Indonesia. Revisi Pertama. Jakarta: Perhimpunan Dokter Paru Indonesia, 2011; p. 1-36.

5. World Health Organization. Global Tuberculosis Report 2015. Genova: WHO Press, 2015.

6. Aditama TY. Tuberkulosis: Pedoman Diagnosis dan Penatalaksanaan di Indonesia. Jakarta: PERPARI, 2006.

7. Aditama TY. MOOT dan MDR. J Respir Indo. 2004;241:57-9.

8. Munir SM, Nawas A, Soetoyo DK. Pengamatan pasien tuberkulosis paru 
dengan Multidrug Resistant (TBMDR) di Poliklinik Paru RSUP Persahabatan. J Respir Indo. 2010;30:92-104.

9. Munawwarah R, Leida I, Wahiduddin. Gambaran faktor risiko pengobatan pasien TB-MDR RS Labuang Baji Kota Makassar Tahun 2013. [Internet] [cited 12 November 2016]. Available from: http://repository.unhas.ac.id/Bitstrea $\mathrm{m} /$ handle/123456789/5530/JURNAL. pdf?sequence $=1$.

10. Nofizar D, Nawas A, Burhan E. Identifikasi faktor risiko tuberkulosis Multidrug Resistant (TB-MDR). Maj Kedokt Indon. 2010;60:537-44.
11. Sarwani D, Nurlaela S, Zahrotul I. Faktor risiko Multidrug Resistant Tuberculosis (MDR-TB). Kemas. 2012;1:60-6.

12. Mulyanto H. Hubungan lima indikator perilaku hidup bersih dan sehat dengan Tuberkulosis Multidrug Resistant. Jurnal Berkala Epidemiologi. 2014;2:355-67.

13. Susanty E, Amir Z, Siagian P, Yunita R, Eyanoer PC. Uji diagnostik GeneXpert MTB/RIF di Rumah Sakit Umum Pusat Haji Adam Malik Medan. Jurnal Biosains. 2015;1:1928. 